\title{
GAMBARAN DETEKSI DINI PENYAKIT GAGAL GINJAL KRONIK PADA MASYARAKAT KECAMATAN TAMBANG, KABUPATEN KAMPAR
}

\author{
Sofiana Nurchayati ${ }^{1}$,' Tukimin bin Sansuwito ${ }^{2}$, Siti Rahmalia ${ }^{3}$ \\ ${ }^{1}$ FKp Universitas Riau, , ${ }^{2}$ Lincoln University College Malaysia, ${ }^{3}$ FKp Universitas Riau \\ Program Studi Ilmu Keperawatan Universitas Riau Jalan Pattimura No 9 Gedung G Pekanbaru Riau \\ Kode Pos 28131 Indonesia \\ Email : sofiananur14@yahoo.co.id
}

\begin{abstract}
Abstrak
Gagal ginjal kronik (GGK) menjadi masalah kesehatan masyarakat global yang prevalensi dan mortalitas penyakit ini cenderung tinggi. GGK merupakan penyakit progresif yang biasanya menimbulkan dampak sosial ekonomi yang besar. Pengukuran tekanan darah dan kadar glukosa darah telah dikenal sebagai cara terbaik untuk deteksi dini penyakit ini. Tujuan penelitian ini untuk mengetahui gambaran deteksi dini GGK pada masyarakat Kecamatan Tambang. Pengukuran tekanan darah dengan menggunakan tensimeter digital yang telah divalidasi dan pemeriksaan kadar gula darah sewaktu dengan menggunakan glukometer telah dilakukan untuk 47 orang yang dipilih berdasarkan teknik simple randome. Analisis univariat menunjukan bahwa sebagian responden didominasi oleh perempuan (43 orang / 91,5\%), lansia awal (17 orang/36,2\%), mengalami hipertensi ringan 20 orang (42,5\%), gula darah normal 46 orang $(97,8 \%)$. Sebagai kesimpulan bahwa meskipun mayoritas penduduk kecamatan tambang mempunyai kadar gula darah yang normal, mereka memiliki salah satu faktor risiko terjadinya GGK jika tekanan darah penderita hipertensi tidak terkontrol. Direkomendasikan kepada Puskesmas sebagai pusat pelayanan di tingkat dasar dalam komunitas/masyarakat hendaknya mampu memberikan pendidikan kesehatan pencegahan GGK secara berkelanjutan sehingga derajat kesehatan masyarakat akan semakin meningkat.
\end{abstract}

Kata kunci: Deteksi dini, gagal ginjal kronik, gula darah, tekanan darah

\begin{abstract}
Chronic renal failure (CRF) became a global public health issue in which the prevalence and mortality of the disease tend to high rate. $\mathrm{CRF}$ is a progressive disease causes a major social-economy impact. Measurement of blood pressure and blood glucose level best known as the early detection method to recognize risk of the disease. This study aimed to determine the early detection of CRF among populations in tambang district. Measurement of blood pressure by using validated digital devices and randome blood sugar by using glucometer were taken from 47 respondent who selected by using simple randome sampling technique. Univariate analysis has shown that respondent dominated by female (43 people/91.5\%), elderly (17 people/ $36.2 \%)$, suffer from mild hypertention 20 people $(42,5 \%)$ and normal blood glucose 46 people $(97,8 \%)$. In conclusion, although populations in Tambang district have normal of blood glucose, they have one risk factor of CRF once their hypertension uncontrolled. Recommended to public health centre as the primary care centre to deliver continum health education to prevent CRF further realizing improvement of public health.
\end{abstract}

Keywords : blood glucose, blood pressure, chronic renal failure, early detection 
Sofiana Nurchayati ${ }^{1}$, Tukimin bin Sansuwito ${ }^{2}$, Siti Rahmalia ${ }^{3}$, Gambaran Deteksi Dini Penyakit Gagal Ginjal Kronik Pada Masyarakat Kecamatan Tambang, Kabupaten Kampar

\section{PENDAHULUAN}

Penyakit gagal ginjal kronik (GGK) merupakan salah satu masalah kesehatan masyarakat global utama dimana prevalensi dan mortalitas penyakit ini yang tinggi (Obrador,et al 2018). Baru baru ini, National Kidney Foundation (2018) telah melaporkan bahwa $10 \%$ penduduk dunia mengalami GGK. Berkaitan dengan itu, Yan Xie, et al (2018) melaporkan bahwa prevalensi global GGK meningkat $86,95 \%$ dari 147.598 .152 kasus di tahun 1990 menjadi 275.929.799 kasus di tahun 2016, angka kematian penduduk global akibat penyakit ini telah meningkat $98,02 \%$ dari 599.200 kematian di tahun 1990 menjadi 1.186.560 kematian di tahun 2016. Crews, et al (2018) melaporkan bahwa sekarang ini penderita GGK di seluruh dunia telah melonjak menjadi 750 juta kasus.

GGK adalah penyakit ginjal yang ditandai oleh hilangnya fungsi ginjal secara gradual dalam jangka waktu yang lama (National Kidney Foundation, 2018). Penyakit ini bersifat progresif yang dapat menimbulkan dampak sosial ekonomi yang besar, baik bagi penderitanya maupun masyarakat dan negara. Penyakit gagal ginjal layaknya fenomena gunung es, hanya sekitar $0,1 \%$ yang terdeteksi dan yang tidak terdeteksi sekitar 11-16\% kasus. Penyebab gagal ginjal di Indonesia sangat khas negara berkembang, yaitu radang ginjal, infeksi ginjal, DM dan hipertensi. Kasus infeksi di Indonesia yang tinggi menjadi penyebab gagal ginjal terbanyak di Indonesia (20\%). Penderita Gagal ginjal berada pada kisaran usia 50 tahun dan usia produktif, sedangkan pada lansia terjadinya gagal ginjal karena DM dan hipertensi yang tidak diberikan pengobatan dengan benar (Nurchayati, 2016).

Etiologi gagal ginjal kronik menurut Smeltzer \& Bare (2006), adalah penyakit sistemik seperti diabetes melitus, glomerulonefritis kronis, pielonefritis, hipertensi yang tidak dapat dikontrol, obstruksi traktus urinarius, lesi herediter seperti penyakit ginjal polikistik, gangguan vaskuler, infeksi, medikasi atau toksik. Lingkungan dan agens berbahaya yang mempengaruhi gagal ginjal kronik mencakup timah, kadmium, merkuri dan kromium. Berkaitan dengan hal ini, Norris dan Nissenson (2008) dan Indonesian Renal Registry dalam Hyodo, et al (2018) melaporkan bahwa prevalensi CKD bervariasi dengan faktor risiko utama seperti diabetes (27\%), 
hipertensi (37\%), glomerulonephritis kronik (10\%), obstructive nephropathy (7\%), pyelonephritis (7\%) dan faktor lain seperti albuminuria, sosial ekonomi, jenis kelamin dan kelompok etnis memainkan peran penting dalam perkembangan prevalensi GGK. Lebih spesifik (CDC, 2019) mengungkapkan bahwa diabetes dan hipertensi merupakan penyebab dua utama GGK. Oleh karena itu direkomendasikan untuk tetap sehat dan terhindar dari GGK, individu hendaknya menjaga kadar gula darah dan tekanan darah agar tetap normal sepanjang masa.

Pada awalnya, penyakit Ginjal kronis tidak menunjukkan gejala yang khas sehingga penyakit ini sering terlambat diketahui. Tanda dan gejala yang timbul karena penyakit Ginjal sangat umum dan dapat ditemukan pada penyakit lain seperti tekanan darah tinggi, perubahan frekuensi buang air kecil dalam sehari, adanya darah dalam urin, mual dan muntah serta bengkak, terutama pada kaki dan pergelangan kaki (Depkes, 2018).

Deteksi dini merupakan kegiatan praklinik untuk menemukan resiko sebelum penyakit itu berkembang sepenuhnya (Medical Dictionary, 2018). Deteksi dini ini sangat penting untuk mendapatkan evidence dalam rangka pencegahan dan lebih lanjut menurunkan insiden penyakit kronis (WHO, 2018). Deteksi dini resiko GGK bisa dilakukan dengan skrining DM, hipertensi, Cardio Vascular Disease dan riwayat kesehatan keluarga (National Institute of Health, 2018). CDC (2018) menyatakan bahwa DM dan hipertensi merupakan faktor dominan penyebab GGK. Oleh karena itu, deteksi dini GGK perlu difokuskan pada pemeriksaan kadar gula darah dan pengukuran tekanan darah untuk menemukan hallmark evidence DM dan hipertensi.

Berdasarkan studi pendahuluan di Kecamantan Tambang, Kabupaten Kampar, Provinsi Riau diperoleh informasi bahwa masyarakat di wilayah ini banyak yang menderita penyakit kencing manis dan tekanan darah tinggi yang tidak terkontrol. Sementara itu, kegiatan deteksi dini GGK dengan pengukuran kadar gula darah dan tekanan darah belum pernah dilakukan.

Tujuan penelitian ini adalah untuk mengetahui gambaran deteksi dini GGK pada masyarakat Kecamatan Tambang, Kabupaten Kampar. 
Sofiana Nurchayati ${ }^{1}$, Tukimin bin Sansuwito ${ }^{2}$, Siti Rahmalia ${ }^{3}$, Gambaran Deteksi Dini Penyakit Gagal Ginjal Kronik Pada Masyarakat Kecamatan Tambang, Kabupaten Kampar

\section{METODE PENELITIAN}

Penelitian kuantitatif ini menggunakan desain penelitian desktiptif dimana data penelitian akan dianalisis menggunakan deskriptif statistik untuk menggambarkan deteksi dini GGK. Data telah dikumpulkan dari 47 responden yang dipilih menggunakan simple randome sampling teknik dari masyarakat kecamatan Tambang, Kampar.

\section{HASIL PENELITIAN}

Tabel 1

Data Demografi responden; jenis kelamin, umur

\begin{tabular}{|lcc|}
\hline Demografi & N & \% \\
\hline $\begin{array}{l}\text { Jenis } \\
\text { kelamin }\end{array}$ & & \\
\hline Laki-laki & 4 & 8,5 \\
\hline Perempuan & 43 & 91,5 \\
\hline Umur & & 10,6 \\
\hline $\begin{array}{l}\text { Dewasa awal } \\
\text { (26-35) }\end{array}$ & 5 & 19,1 \\
\hline $\begin{array}{l}\text { Dewasa } \\
\text { akhir (36-45) }\end{array}$ & 9 & 36,2 \\
\hline $\begin{array}{l}\text { Lansia awal } \\
\text { (46-55) }\end{array}$ & 17 & 29,4 \\
\hline $\begin{array}{l}\text { Lansia akhir } \\
\text { (56-65) }\end{array}$ & 15 & 4,7 \\
\hline $\begin{array}{l}\text { Manula } \\
\text { (>65) }\end{array}$ & 1 & \\
\hline
\end{tabular}

Berdasarkan tabel 1 didapatkan bahwa responden dalam penelitian ini didominasi oleh perempuan sebanyak 43 responden $(91,5 \%)$ dan umur terbanyak adalah lansia awal sebanyak 17 responden (36,2\%).

\section{Tabel 2}

Nilai hasil pengukuran tekanan darah

\begin{tabular}{|c|c|c|c|}
\hline No & $\begin{array}{l}\text { Tekanan Darah } \\
\text { (Sistolik) }\end{array}$ & $\mathbf{N}$ & $(\%)$ \\
\hline 1 & $\begin{array}{l}<120 \quad \mathrm{mmHg} \\
\text { (Normal) }\end{array}$ & 20 & 42,5 \\
\hline 2 & $\begin{array}{l}120-150 \\
\text { (Hipertensi } \\
\text { ringan) }\end{array}$ & 20 & 42,5 \\
\hline 3 & $\begin{array}{l}>150 \text { (Hipertensi } \\
\text { sedang) }\end{array}$ & 7 & 15 \\
\hline 4 & $\begin{array}{l}>200 \quad \text { (hipertensi } \\
\text { berat) }\end{array}$ & 0 & 0 \\
\hline
\end{tabular}

Berdasarkan hasil pengukuran tekanan darah pada tabel 2 didapatkan bahwa sebagian mengalami hipertensi ringan sebanyak 20 responden $(42,5 \%)$.

\section{Tabel 3}

Nilai hasil pemeriksaan glukosa darah sewaktu

\begin{tabular}{lllc}
\hline No & $\begin{array}{l}\text { Nilai Glukosa } \\
\text { Darah sewaktu }\end{array}$ & N & $\%$ \\
\hline 1 & $<200$ & 46 & 97,8 \\
\hline 2 & $>200$ & 1 & 2,2 \\
\hline
\end{tabular}

Berdasarkan hasil pemeriksaan glukosa darah sewaktu pada tabel 3 didapatkan bahwa mayoritas memiliki nilai kadar gula darah sewaktu yang normal <200 mg\% sebanyak 46 responden $(97,8 \%)$. 


\section{PEMBAHASAN}

Berdasarkan hasil penelitian didapatkan bahwa masyarakat kecamatan Tambang yang menjadi responden didominasi oleh perempuan dan usia lansia. Meskipun perempuan mempunyai resiko GGK yang lebih rendah dibanding laki-laki (Fanelli, 2017), mereka harus harus tetap waspada dengan umur yang semakin bertambah dan hipertensi yang dialaminya. Berkaitan dengan ini (Andrew, et al , 2005) menyatakan bahwa fungsi ginjal dan renal survival akan menurun berbanding lurus dengan pertambahan umur. Chang (2016) menyatakan bahwa hipertensi yang tidak terkontrol merupakan faktor yang signifikan menjadi penyebab GGK.

Penelitian ini menunjukkan bahwa sebagian besar responden menderita hipertensi ringan dan sedang. Hal ini dapat menjadi indikator adanya faktor resiko dominan yang dapat menyebabkan GGK apabila tidak diberikan penanganan dengan baik (Hyodo, et al, 2018). Berkaitan dengan itu, (Tedla, 2011) menegaskan bahwa mengontrol tekanan darah dapat mengurangkan resiko terjadinya gagal ginjal kronik.

Berdasarkan hasil pemeriksaan glukosa darah sewaktu ditemukan bahwa 97,8 \% responden dengan kadar gula darah $<200$ $\mathrm{mg} \%$ dan hanya $2.2 \%$ responden memiliki kadar gula darah >200 mg\%, hal ini berarti bahwa hampir semua peserta memiliki kadar glukosa darah yang normal. Namun hal ini perlu diwaspadai juga, mengingat semua responden berada pada usia produktif dan sebagian besar dari mereka berusia 50 tahun ke atas yang merupakan usia beresiko terjadinya hipertensi (Buford, 2016) dan GGK (Suharjono, 2008). Secara fisiologis pada kelompok usia di atas, individu juga beresiko mengalami penurunan sensitivitas membrane sel terhadap insulin yang bisa menyebabkan terjadinya resistensi insulin sehingga meningkatkan resiko terjadinya Diabetes Mellitus (DM) jenis II (Park, 2014). CDC (2018) menegaskan bahwa penyakit DM yang tidak terkontrol dengan baik merupakan faktor resiko dominan penyebab GGK.

\section{SIMPULAN}

a. Responden dalam penelitian ini didominasi oleh perempuan sebanyak 43 responden $(91,5 \%)$ dan umur terbanyak 
Sofiana Nurchayati ${ }^{1}$, Tukimin bin Sansuwito ${ }^{2}$, Siti Rahmalia ${ }^{3}$, Gambaran Deteksi Dini Penyakit Gagal Ginjal Kronik Pada Masyarakat Kecamatan Tambang, Kabupaten Kampar

adalah lansia awal sebanyak 17 responden $(36,2 \%)$.

b. Hasil pengukuran tekanan darah didapatkan bahwa sebagian mengalami hipertensi ringan sebanyak 20 responden $(42,5 \%)$

c. Hasil pemeriksaan glukosa darah sewaktu didapatkan bahwa mayoritas memiliki nilai kadar gula darah sewaktu yang normal $<200 \mathrm{mg} \%$ sebanyak 46 responden $(97,8 \%)$

Disimpulkan bahwa pada responden di wilayah Kecamatan Tambang, Kabupaten Kampar memiliki risiko terjadinya GGK setelah dilakukan pemeriksaan tekanan darah dan gula darah sewaktu untuk mendeteksi dini GGK.

\section{SARAN}

\section{a. Bagi institusi pendidikan}

Kegiatan penelitian ini dapat dijadikan informasi yang terkait dengan masalah kesehatan, terkait dengan upaya deteksi dini GGK yang dilakukan untuk dapat menurunkan angka morbiditas pada GGK.

\section{b. Bagi institusi pelayanan kesehatan}

Puskesmas sebagai pusat pelayanan di tingkat dasar dalam komunitas/masyarakat hendaknya mampu memberikan pendidikan kesehatan secara berkelanjutan secara terus menerus sehingga derajat kesehatan masyarakat akan semakin meningkat.

\section{DAFTAR PUSTAKA}

Andrew D., Riccardo, P., Magistroni, N. Wang, K., Johnson, A., Fain, P.R., Dicks E., Parfrey, P., George, P. and Pei, Y. (2005), Progressive Loss of Renal Function Is an Age-Dependent Heritable Trait in Type 1 Autosomal Dominant Polycystic Kidney Disease. Journal of American Society Nephroligy.16 (3) 755-762;

DOI: https://doi.org/10.1681/ASN.200409075 8

Buford T. W. (2016). Hypertension and aging. Ageing research reviews, 26, 96-111. doi:10.1016/j.arr.2016.01.007

CDC (2018) Chronic Kidney Disease in the United States. Centers for Disease Control and Prevention. Atlanta, GA: US Department of Health and Human Services. Available at https://www.cdc.gov/kidneydisease/publ ications-resources/2019-national-facts.ht $\underline{\mathrm{ml}}$

Chang, P. Y., Chien, L. N., Lin, Y. F., Wu, M. S., Chiu, W. T., \& Chiou, H. Y. (2016). Risk factors of gender for renal progression in patients with early chronic kidney disease. Medicine, 95(30), e4203.

Crews D.C., Bello A.K. and Saadi G. (2018) Burden, Access, and Disparities in 
Kidney Disease. World Kidney Day

2019: Editorial. Kidney Disease

2019;5,pp.126-133

Depkes. 2018. Cegah dan Kendalikan Penyakit

Ginjal dengan CERDIK dan PATUH.

http://www.depkes.go.id

Dharmeizar. 2015. Pernefri Edukasi Masyarakat Tentang Kesehatan Ginjal. http://www.gatra.com/

Fanelli, C., Delle, H., Cavaglieri, R. C., Dominguez, W. V., \& Noronha, I. L. (2017). Gender Differences in the Progression of Experimental Chronic Kidney Disease Induced by Chronic Nitric Oxide Inhibition. BioMed research international, pp.1-10.

Hasan, M., Sutradhar, I, Rajat Das Gupta, D.R. dan Sarker, M. (2018) Prevalence of chronic kidney disease in South Asia: a systematic review. BMC Nephrology. 19(291)pp. 1-6. https://doi.org/

Hyodo, T., Fukagawa1, M., Hirawa, N., Hayashi, M., Kosaku, N., Chan, S., Souvannamethy, P., Dorji, M., Chuluuntsetseg, V. and I. Gde Raka Widiana (2019). Present status of renal replacement therapy in Asian countries: Cambodia, Laos, Mongolia, Bhutan, and Indonesia. Renal Replacement Therapy. 5(12).pp.1-11. https://doi.org/

Lubis, HR. 2015. Pernefri : Jumlah Penderita Ginjal Terus Naik. http://nasional.republika.co.id/berita/nasi onal/daerah/15/03/12/nl3no6-pernefri-ju mlah-penderita-ginjal-terus-naik

Medical Dictionary (2019). Definition of Early Detection. Mosby's Dictionary of Complementary and Alternative Medicine. from https://medical-dictionary.thefreediction ary.com/

National Institute of Health (NIH) (2018) Identify \& Evaluate Patients with Chronic Kidney Disease. The National Institute of Diabetes and Digestive and Kidney Disease, Health Information Center. US Departement of Health and Human Service. USA gov. available at https://www.niddk.nih.gov/

National Kidney Foundation (2018) Global Fact about Kidney Disease. National Kidney Foundation, Inc., 30 East 33rd Street, New York. Bisa diakses di https://www.kidney.org/

Norris, K and Nissenson, AL. 2008. Race, Gender, and Socioeconomic Disparities in CKDin the United States. www.jasn.org

Nurchayati, S. 2016. Implementasi Self Care Model Dalam Upaya Meningkatkan Kualitas Hidup Penderita Gagal Ginjal Kronik. Jurnal Keperawatan Sriwijaya, Volume 3 - Nomor 2, Juli 2016, ISSN No 23555459

Obrador, GT., Gary C Curhan, GC. Dan Motwani, S. (2018) Epidemiology of chronic kidney disease. Wolters Kluwer. UpToDate, Inc. All right reserved https://www.uptodate.com/

Park, M. H., Kim, D. H., Lee, E. K., Kim, N. D., Im, D. S., Lee, J., Chung, H. Y. (2014). Age-related inflammation and insulin resistance: a review of their intricate interdependency. Archives of pharmacal research, 37(12), 1507-1514. doi:10.1007/s12272-014-0474-6

Smeltzer \& Bare. (2006). Buku Ajar Keperawatan Medikal Bedah. Edisi 8 Volume 2. Jakarta: EGC

Tedla, F. M. Brar, A. Browne, R.and Brown, C. 
Sofiana Nurchayati ${ }^{1}$, Tukimin bin Sansuwito ${ }^{2}$, Siti Rahmalia ${ }^{3}$, Gambaran Deteksi Dini Penyakit Gagal Ginjal Kronik Pada Masyarakat Kecamatan Tambang, Kabupaten Kampar

(2011) Hypertension in Chronic Kidney

Disease: Navigating the Evidence,

International Journal of Hypertension,

vol. 2011, pp.1-9. https://doi.org/

WHO (2019) Screening Group: Section of

Early Detection and Prevention.

International Agency for Research on

Cancer. IARC Allright Reserved

Available at https://www.iarc.fr/

Yan Xie, Benjamin Bowe, Ali H. Mokdad,

Hong Xian, Yan Yan, Tingting Li,

Geetha Maddukuri, Cheng-You Tsai,

Tasheia Floyd and Ziyad Al-Aly, (2018)

Analysis of the Global Burden of Disease

study highlights the global, regional, and

national trends of chronic kidney disease

epidemiology from 1990 to 2016.

Kidney International. 94,pp. 567-581.

https://doi.org/ 